\title{
Correction to: Value of endometrial echo pattern transformation after hCG trigger in predicting IVF pregnancy outcome: a prospective cohort study
}

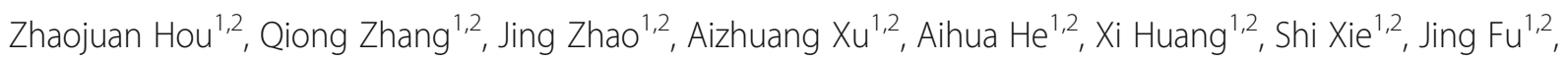
Lan Xiao ${ }^{1,2}$ and Yanping $\mathrm{Li}^{1,2^{*}}$

\section{Correction to: Reprod Biol Endocrinol 17, 74 (2019)}

https://doi.org/10.1186/s12958-019-0516-5

Following publication of the original article [1], the authors reported an error in the order of the figures.

The Fig. 1 published is supposed to be Fig. 5. The Fig. 2 published is supposed to be Fig. 1. The Fig. 3 published is supposed to be Fig. 2. The Fig. 4 published is supposed to be Fig. 3. The Fig. 5 published is supposed to be Fig. 4. The correct order of the figures are as follows:

The publishers apologise for this error.

Published online: 08 September 2020

\section{Reference}

1. Hou Z, Zhang Q, Zhao J, et al. Value of endometrial echo pattern

transformation after hCG trigger in predicting IVF pregnancy outcome: a prospective cohort study. Reprod Biol Endocrinol. 2019;17:74 https://doi.org/ 10.1186/s12958-019-0516-5.

\footnotetext{
The original article can be found online at https://doi.org/10.1186/s12958019-0516-5.

* Correspondence: stephaniehou@sina.com

'Department of Reproductive Medicine, Xiangya Hospital, Central South University, 87 Xiangya Road, Changsha City, Hunan Province 410008, People's Republic of China

${ }^{2}$ Clinical Research Center For Women's Reproductive Health In Hunan Province, 87 Xiangya Road, Changsha City, Hunan Province 410008, People's Republic of China
}

(c) The Author(s). 2020 Open Access This article is licensed under a Creative Commons Attribution 4.0 International License, which permits use, sharing, adaptation, distribution and reproduction in any medium or format, as long as you give appropriate credit to the original author(s) and the source, provide a link to the Creative Commons licence, and indicate if changes were made. The images or other third party material in this article are included in the article's Creative Commons licence, unless indicated otherwise in a credit line to the material. If material is not included in the article's Creative Commons licence and your intended use is not permitted by statutory regulation or exceeds the permitted use, you will need to obtain permission directly from the copyright holder. To view a copy of this licence, visit http://creativecommons.org/licenses/by/4.0/ The Creative Commons Public Domain Dedication waiver (http://creativecommons.org/publicdomain/zero/1.0/) applies to the data made available in this article, unless otherwise stated in a credit line to the data. 

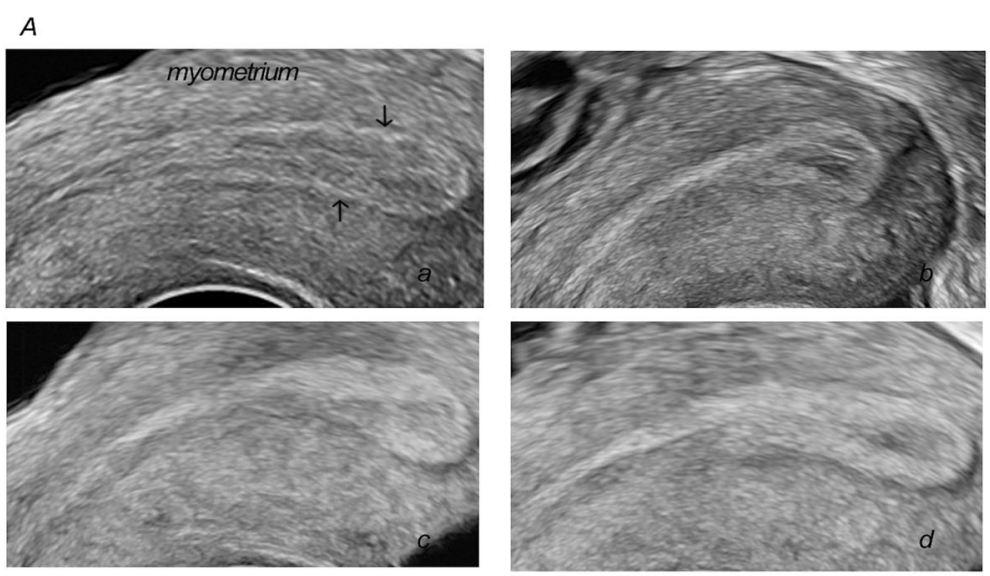

$B$
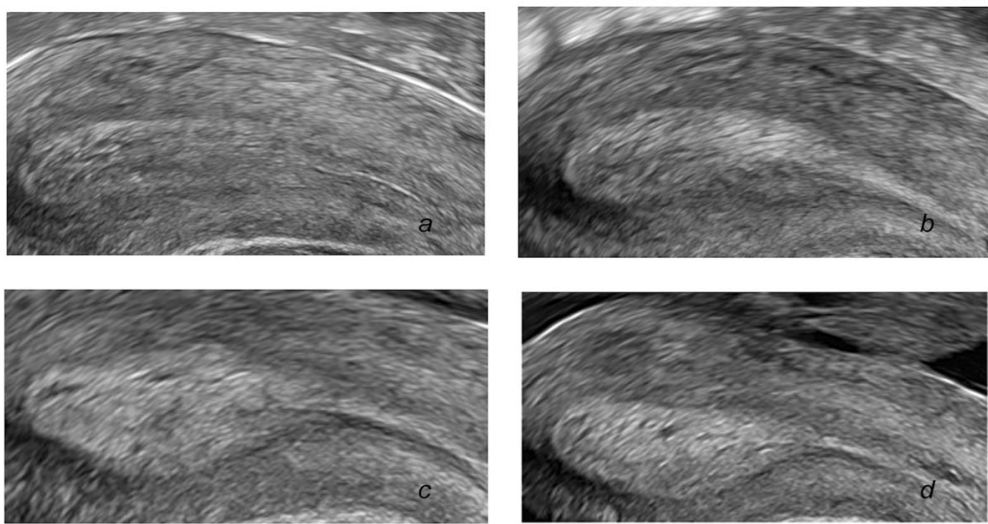

Fig. 1 Endometrial echogenicity in infertile women after hCG trigger during $\mathrm{COH}$ cycles. (A) Endometrial echogenicity with non-pregnant women. (B) Endometrial echogenicity with pregnant women. The black arrow points to the endometrium-myometrium interfaces. a, HCG day; b, $\mathrm{OPU}+1 ; \mathrm{c}, \mathrm{OPU}+2 ; \mathrm{d}, \mathrm{OPU}+3$ 


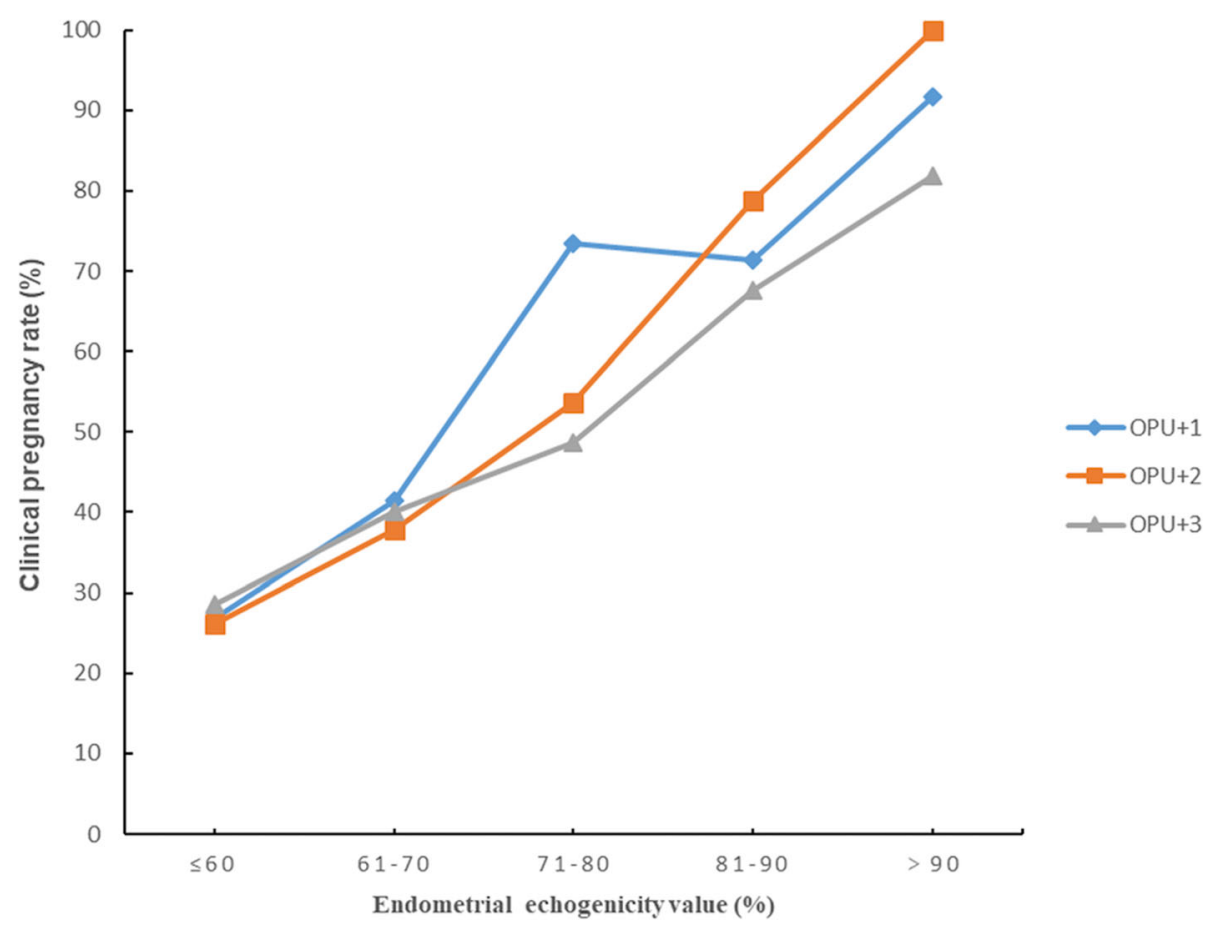

Fig. 2 Clinical pregnancy rates in different endometrial echogenicity groups assessed on OPU $+1, \mathrm{OPU}+2$ and $\mathrm{OPU}+3$

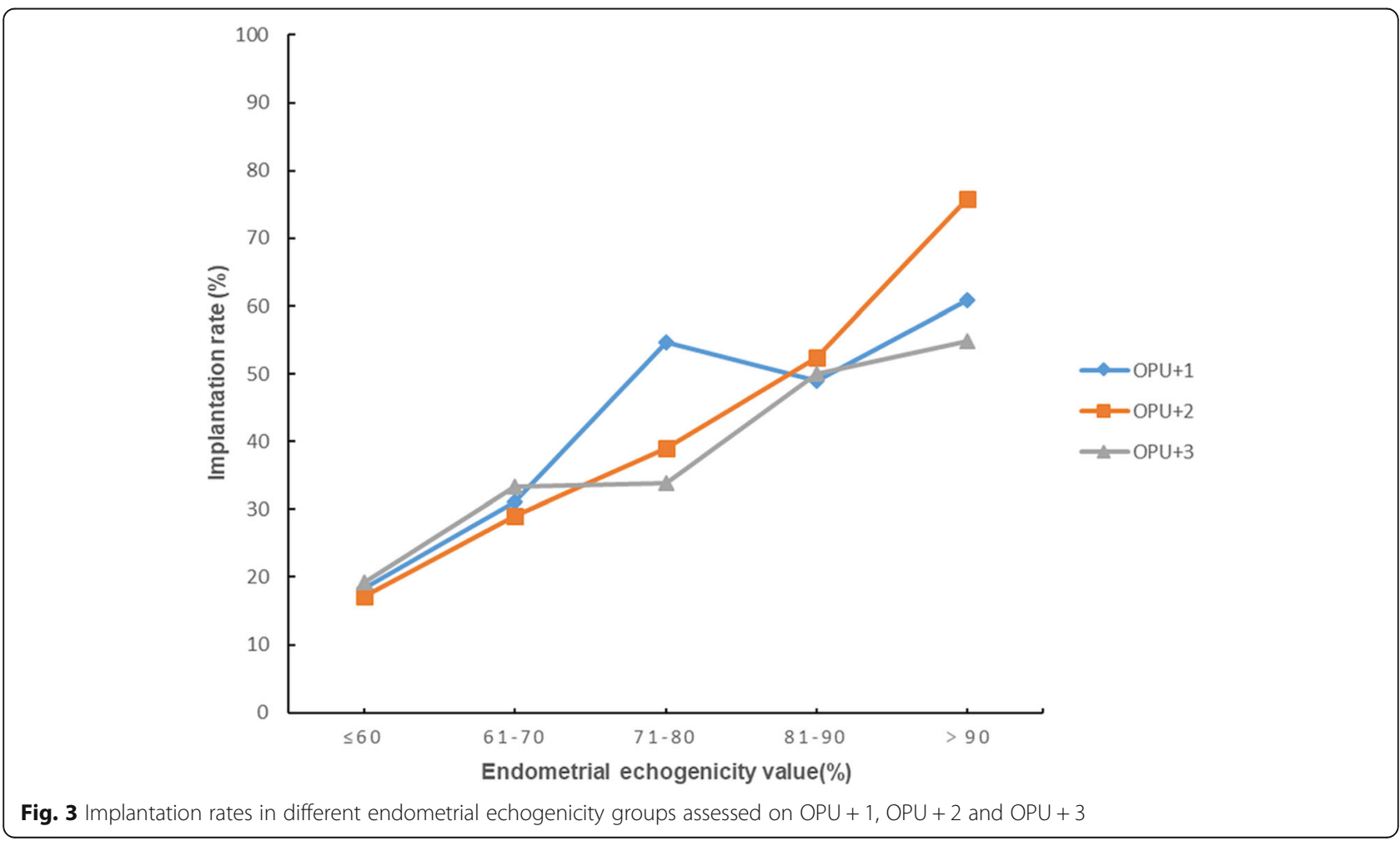




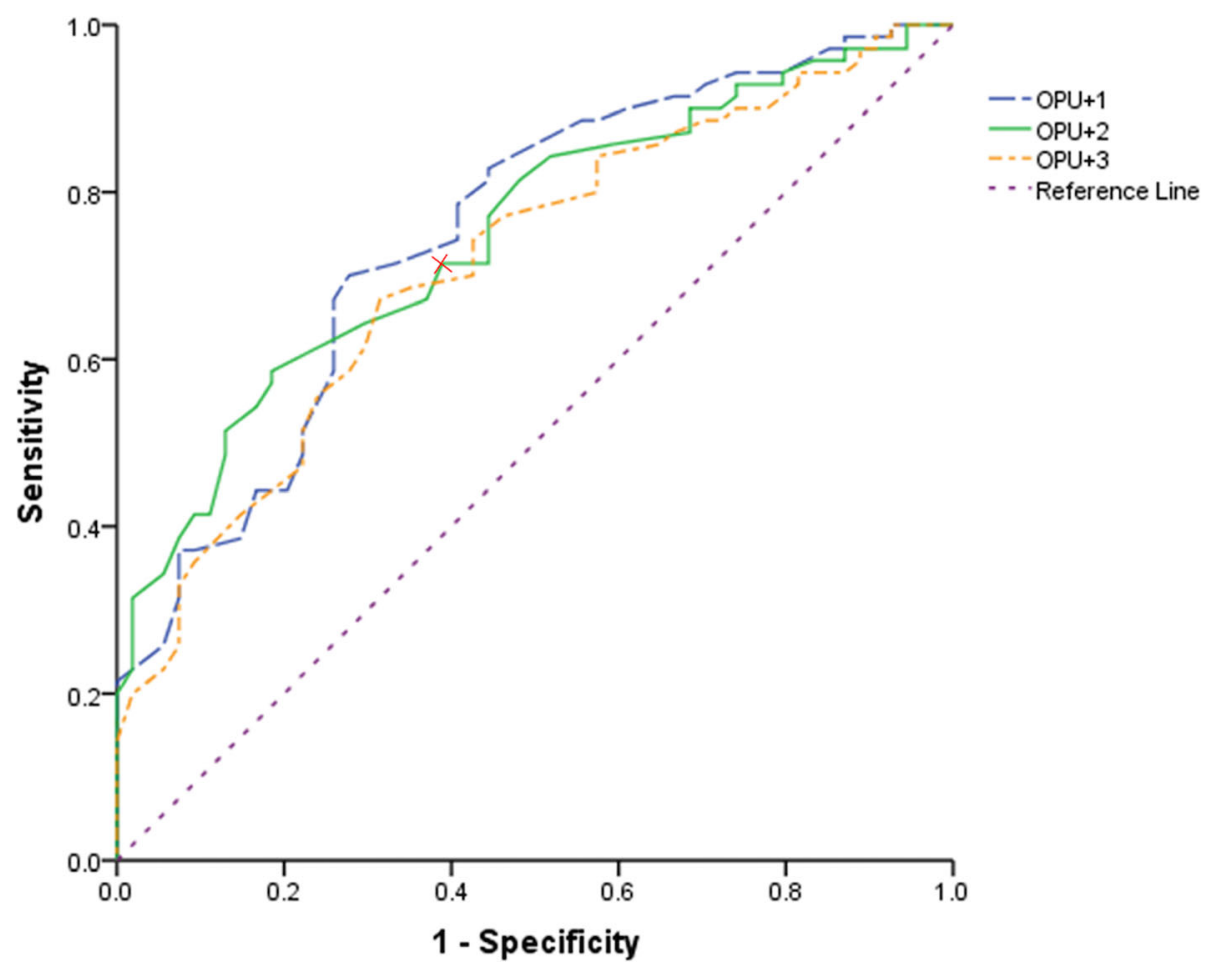

Fig. 4 ROC curve of endometrial echogenicity value on OPU +1,2,3 for successful clinical pregnancy. The areas under the ROC curve were 0.738(95\%Cl:0.656-0.819), 0.765(95\%Cl: 0.688-0.842), 0.714(95\%Cl:0.624-0.804) respectively on OPU + 1, OPU + 2 and OPU + 3. Endometrial echogenicity value on OPU +2 had the most predictive value, and the cutoff value was $76.5 \%$. The sensitivity was $61.3 \%$ and the specificity was $82.0 \%$ 


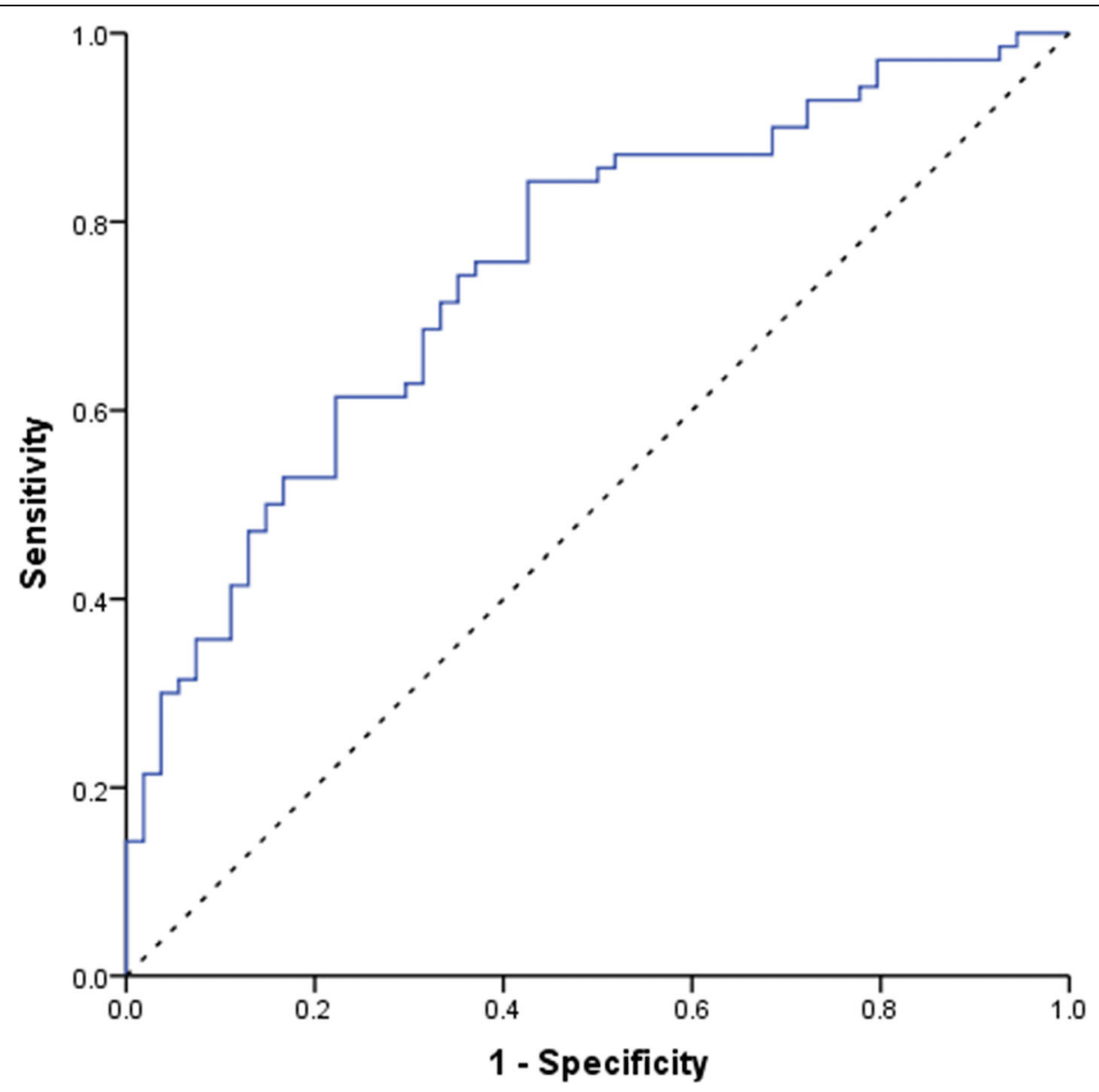

Fig. 5 ROC curve of the combination of endometrial echogenicity value on OPU +2 and thickness on OPU +3 . The areas under the ROC curve was 0.751 (95\%Cl:0.665-0.836) 